\title{
1,2,3-Triazolylidenes as Versatile Abnormal Carbene Ligands for Late Transition Metals
}

\author{
Paulson Mathew, ${ }^{\dagger}$ Antonia Neels, ${ }^{\ddagger}$ and Martin Albrecht ${ }^{\star, \dagger}$ \\ Department of Chemistry, University of Fribourg, Chemin du Musée 9, CH-1700 Fribourg, Switzerland, and Centre \\ Suisse d'Electronique et de Microtechnique (CSEM), Rue Jaquet-Droz 1, CH-2002 Neuchâtel, Switzerland
}

$\mathrm{N}-\mathrm{Heterocyclic}$ carbenes (NHCs) have become very popular ligands in transition metal chemistry predominantly due to their efficiency in improving catalyst activities. ${ }^{1}$ Their impact, often superior to that of ubiquitous phosphines, has generally been rationalized by the covalent $\mathrm{M}-\mathrm{C}_{\text {carbene }}$ bond and by the strong donor ability of NHCs. ${ }^{2}$ Arduengo-type imidazolylidenes have been used most widely (A, Chart 1), presumably because the free carbene is extensively stabilized by heteroatoms adjacent to the carbene, which makes them easy to handle. ${ }^{3}$ Pioneering work by Bertrand and others evidenced that singlet carbenes may be isolated also with less pronounced heteroatom stabilization. ${ }^{4 a}$ For example, carbenes $\mathbf{B}-\mathbf{D}$ were analyzed by crystallography, ${ }^{4 \mathrm{~b}-\mathrm{d}}$ while more reactive $\mathbf{E}$ and $\mathbf{F}$ have been analyzed in situ. ${ }^{4 e, f}$ In contrast, abnormal $^{5}$ carbenes such as $\mathbf{G}$ have not been characterized in their free form, perhaps due to the small contribution of the carbenoic resonance form. ${ }^{6}$ First results indicate that such abnormal carbenes are stronger donors than carbenes $\mathbf{A}-\mathbf{E},{ }^{7}$ which should provide new opportunities for catalyst design. ${ }^{7 \mathrm{~b}, 8}$

Here we have applied the $[3+2]$ cycloaddition of acetylenes with azides ("click" chemistry) as a versatile and flexible method" for synthesizing heterocycles that are effective precursors for a new class of abnormal carbenes, thus greatly expanding the family of carbene ligands. Substitution of 1,2,3-triazoles at the 1- and 4-position is virtually unlimited due to the accessibility of a large variety of acetylenes and azides. ${ }^{10}$ Copper-mediated cyclization allows for introducing functional groups into the triazole framework for diverse purposes, e.g., for surface functionalization, bioconjugate immobilization, or supramolecular applications. ${ }^{11}$ We have used the simple triazoles $\mathbf{1 a}$ and $\mathbf{1 b}$ for further ligand synthesis (Scheme 1). Alkylation of the 3-position using MeI was regioselective according to nuclear Overhauser experiments and afforded the triazolium salts $\mathbf{2}$ as abnormal NHC precursors.

Since free 1,2,3-triazolylidenes tend to decompose, ${ }^{12}$ metalation of the triazolium salts $\mathbf{2}$ was probed by direct metal insertion via $\mathrm{C}-\mathrm{H}$ bond activation as well as by using a transmetalation protocol. Direct metalation with $\mathrm{Pd}(\mathrm{OAc})_{2}$ was performed according to methods that have previously been established for palladation of normal and abnormal NHC ligand precursors (Scheme 1). ${ }^{13}$ Thermally induced $\mathrm{C}-\mathrm{H}$ bond activation afforded the dinuclear monocarbene complex $\mathbf{3}$ as well as minor quantities of a mononuclear dicarbene species. X-ray structural analyses of $\mathbf{3 b}$ unambiguously confirmed the connectivity pattern (Figure 1). The $\mathrm{Pd}-\mathrm{C}$ bond length is 1.967(13) $\AA$ and hence relatively short when compared to other $\mathrm{Pd}-\mathrm{C}_{\mathrm{NHC}}$ bond distances. ${ }^{13}$ Characteristic for abnormal carbenes, the triazolylidene (trz) ligand displays a small carbene angle $\left(\mathrm{N} 1-\mathrm{C} 1-\mathrm{C} 2,103^{\circ}\right)$. The heterocycle is twisted out of the palladium square plane by $\sim 75^{\circ}$, presumably due to the bulk

\footnotetext{
${ }^{\dagger}$ University of Fribourg.

CSEM Neuchâtel.
}

Chart 1. Carbenes with Different Degrees of Heteroatom Stabilization

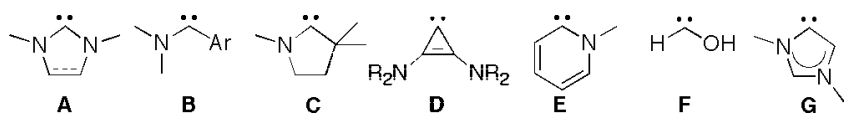

Scheme 1. Palladation of Triazolium Salts via $\mathrm{C}-\mathrm{H}$ bond Activation

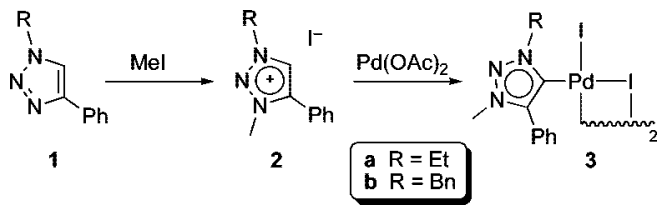

in the $\alpha$-position of the carbene carbon. In the ${ }^{13} \mathrm{C}\left\{{ }^{1} \mathrm{H}\right\}$ NMR spectrum, the metal-bound carbon appears at $\delta_{\mathrm{C}} 159$ (3a) and, thus, at significantly lower field than in related abnormal iodopalladium carbenes featuring only one heteroatom adjacent to the carbene carbon.

Similar $\mathrm{C}-\mathrm{H}$ bond activation was observed with $\mathrm{Ag}_{2} \mathrm{O}$ (Scheme 2). ${ }^{14}$ According to NMR spectroscopy, formation of the Ag-triazolylidene complex $\mathbf{4}$ is complete within $2 \mathrm{~h}$ by virtue of the disappearance of the acidic triazolium proton in $\mathbf{2 a}\left(\delta_{\mathrm{H}} 9.52\right)$. In solution, this silver-carbene complex, which has thus far precluded full structure analysis, slowly decomposed ( $t_{1 / 2}$ ca. $20 \mathrm{~h}$ at RT). Mass spectrometry measurements indicate a main fragment at $\mathrm{m} / \mathrm{z}$, $=481.2$, which is consistent with the proposed $\mathrm{Ag}(\operatorname{trz})_{2}$ structure 4 (calculated $\mathrm{M}^{+}$481.1) rather than a monocarbene AgI(trz) species. Irrespective of its exact structure, complex $\mathbf{4}$ proved to be a highly efficient carbene transfer agent. Transmetalation was successfully performed with $\mathrm{Ru}^{\mathrm{II}}, \mathrm{Rh}^{\mathrm{I}}$, and $\mathrm{Ir}^{\mathrm{I}}$ precursors and afforded the corresponding triazolylidene complexes 5-7, illustrating the versatility of this ligand system in binding toward metal centers (Scheme 2, $\operatorname{cod}=1,5$-cyclooctadiene; see also Figure 2a).

Insight into the donor properties of this new abnormal carbene ligand was obtained by replacing the ancillary diene in complexes $\mathbf{6 a}$ and $7 \mathbf{a}$ with $\mathrm{CO}$ ligands as diagnostic IR probes $(\mathbf{6 b}$ and $\mathbf{7 b}$, respectively). A cis arrangement of the $\mathrm{CO}$ ligands was evidenced from a crystal structure determination of $\mathbf{7 b}$ (Figure $2 b$ ). Retention of this conformation in solution is supported by the presence of two inequivalent signals in the ${ }^{13} \mathrm{C}$ NMR spectrum. Assignment of the carbonyl resonances was facilitated by ligand exchange reactions using isotopically labeled ${ }^{13} \mathrm{CO}$. This allowed the metalbound triazolylidene carbon to be unambiguously identified, $\delta_{\mathrm{C}}$ 161.2 in $\mathbf{6 b}$ and 162.0 in $\mathbf{7 b}$. The small ${ }^{103} \mathrm{Rh}-{ }^{13} \mathrm{C}$ coupling constant in $\mathbf{6 b}\left({ }^{1} J_{\mathrm{RhC}}=39.4 \mathrm{~Hz}\right)$ suggests a relatively weak $\mathrm{Rh}-\mathrm{C}_{\mathrm{trz}}$ bond. ${ }^{15}$

The CO stretch vibrations of the iridium complex $7 \mathbf{b}\left(v_{\text {as }}=2062\right.$ $\mathrm{cm}^{-1}, v_{\mathrm{s}}=1979 \mathrm{~cm}^{-1}$ ) provide a direct probe for the donor 


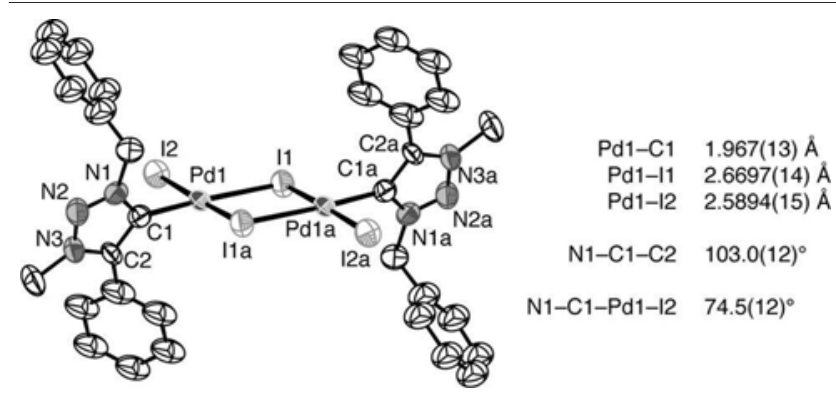

Figure 1. ORTEP plot and relevant bond lengths and angles of $\mathbf{3 b}(50 \%$ probability, only one of the two independent molecules shown).

Scheme 2. Metallation of Triazolium Salts via Transmetallation
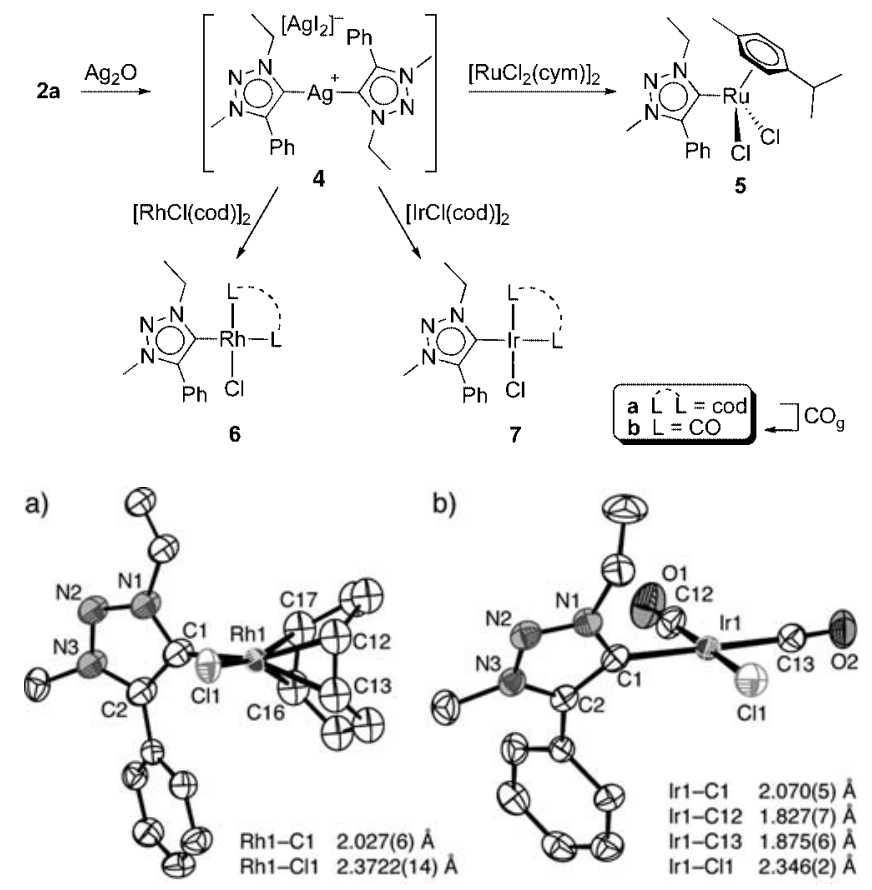

Figure 2. ORTEP plot of $\mathbf{6 a}$ (a) and $\mathbf{7 b}$ (b; $50 \%$ probability each).

properties of the triazolylidene ligand. For complexes of the type $\operatorname{IrCl}(\mathrm{CO})_{2} \mathrm{~L}$, a linear correlation between $v_{\text {average }}(\mathrm{CO})$ and the Tolman electronic parameter (TEP) of $\mathrm{L}$ has been established. ${ }^{16}$ Using linear regression methods, a TEP $(\operatorname{trz})=2047.4 \mathrm{~cm}^{-1}$ has been calculated for $\mathbf{7 b}$. This value compares well with the most basic 2-imidazolylidenes A (e.g., TEP(ICy) $=2049.6$; ICy $=N, N^{\prime}$-dicyclohexylimidazol-2-ylidene), though it is higher than the TEP of other abnormal carbenes. ${ }^{16 a}$ The donor properties of the trz ligand may be further modified by adjusting the substitution pattern of the heterocycle, thus filling the gap between the most basic normal carbenes and the exceptionally strongly donating 4-imidazolylidenes. Given the high diversity in $[3+2]$ click-type cycloadditions, ligand modifications will constitute a straightforward methodology for tailoring the electronic properties of the metal center as well as the steric parameters. Catalytic applications of these new abnormal carbene complexes are currently being investigated.

In summary, 1,3,4-substituted 1,2,3-triazolium salts are readily accessible and highly modular precursors for the synthesis of new abnormal NHC complexes with a variety of transition metals. The triazole framework is particularly versatile for introducing substituents (e.g., chelating groups) and functionalities such as dendritic supports or molecular recognition sites. Considering this flexibility in ligand synthesis, the versatility of metal insertion, and the high impact of abnormal carbenes in catalysis, abnormal triazolylidene complexes are expected to have great potential for the development of new catalysts with unprecedented ligand-induced reactivity patterns.

Acknowledgment. We thank A. Poulain for synthetic assistance. This work was financially supported by the Swiss National Science Foundation and by DST (India) through a BOYSCAST fellowship (to P.M.). M.A. gratefully acknowledges an Assistant Professorship of the Alfred Werner Foundation.

Note Added after ASAP Publication. IR data for $\mathbf{7 b}$ were corrected in the version published October 8, 2008.

Supporting Information Available: Experimental procedures and spectroscopic data for all reported complexes, and CIF files for structures $\mathbf{3 b}, \mathbf{6 a}$, and $\mathbf{7 b}$. This material is available free of charge via the Internet at http://pubs.acs.org.

\section{References}

(1) (a) Trnka, T. M.; Grubbs, R. H. Acc. Chem. Res. 2001, 34, 18. (b) Kantchev, E. A. B.; O'Brien, C. J. O.; Organ, M. G. Angew. Chem., Int. Ed. 2007, 46, 2768. (c) Nolan, S. P. N-Heterocyclic Carbenes in Synthesis; WileyVCH: Weinheim, 2006.

(2) (a) Bourissou, D.; Guerret, O.; Gabbai, F. P.; Bertrand, G. Chem. Rev. 2000, 100, 39. (b) Hahn, E. F.; Jahnke, M. C. Angew. Chem., Int. Ed. 2008, 47,3122 .

(3) (a) Arduengo, A. J.; Harlow, R. L.; Kline, M. J. Am. Chem. Soc. 1991, 113,361 .

(4) (a) Moss, R. A., Platz, M. S., Jones, M., Eds. Reactive Intermediate Chemistry; Wiley-Interscience: Hoboken, NJ, 2004. (b) Sole, S.; Gornitzka, H.; Schoeller, W. W.; Bourissou, D.; Bertrand, G. Science 2001, 292, 1901. (c) Lavallo, V.; Canac, Y.; Präsang, C.; Donnadieu, B.; Bertrand, G. Angew. Chem., Int. Ed. 2005, 44, 5705. (d) Lavallo, V.; Canac, Y.; Donnadieu, B.; Schoeller, W. W.: Bertrand, G. Science 2006, 312, 722. (e) Lavorato, D.; Terlouw, J. K.; Dargel, T. K.; Koch, W.; McGibbon, G. A.; Schwarz, H. J. Am. Chem. Soc. 1996, 118, 11898. (f) Schreiner, P. R.; Reisenauer, H. P.; Pickard, F. C.; Simmonett, A. C.; Allen, W. D.; Matyus, E.; Csaszar, A. G. Nature 2008, 453,906

(5) Carbenes are generally termed abnormal, if no neutral canonical resonance form exists. The term has been originally used for 4-imidazolylidenes; see: (a) Gründemann, S.; Kovacevic, A.; Albrecht, M.; Faller, J. W.; Crabtree, R. H. J. Am. Chem. Soc. 2002, 124, 10473 Different types of abnormal N-heterocyclic carbenes have been reported since: (b) Koizumi, T.; Tomon, T.; Tanaka, K. Organometallics 2003, 22, 970. (c) Han, Y.; Huynh, H. V.; Tan, G. K. Organometallics 2007, 26, 6581. For a review, see: (d) Albrecht, M. Chem. Commun. 2008, 3601.

(6) In abnormal carbenes, zwitterionic resonance structures may be even more relevant than in normal NHC complexes, and hence, the term "carbene" needs some caution ( $c f$. ref $5 \mathrm{~d})$.

(7) (a) Chianese, A. R.; Kovacevic, A.; Zeglis, B. M.; Faller, J. W.; Crabtree, R. H. Organometallics 2004, 23, 2461. (b) Heckenroth, M.; Kluser, E.; Neels, A.; Albrecht, M. Angew. Chem., Int. Ed. 2007, 46, 6293.

(8) (a) Lebel, H.; Janes, M. K.; Charette, A. B.; Nolan, S. P. J. Am. Chem. Soc. 2004, 126, 5046. (b) Yang, L.; Krüger, A.; Neels, A.; Albrecht, M. Organometallics 2008, 27, 3161.

(9) (a) Kolb, H.; Finn, M. G.; Sharpless, K. B. Angew. Chem., Int. Ed. 2001, 40, 2004. (b) Bock, V. D.; Hiemstra, H.; van Maarseveen, J. H. Eur. J. Org. Chem. 2006, 51

(10) (a) Devaraj, N. K.; Dnolfo, P. H.; Chidsey, C. E. D.; Collman, J. P. J. Am. Chem. Soc. 2006, 128, 1794. (b) Fernandez-Megia, E.; Correa, J.; Riguera, R. Biomacromolecules 2006, 7, 3104. (c) Gopin, A.; Ebner, S.; Attali, B.; Shabat, D. Bioconjugate Chem. 2006, 17, 1432. (d) Hawker, C. J.; Wooley, K. L. Science 2005, 309, 1200. (e) Burley, G. A.; Gierlich, J.; Mofid, M. R.; Nir, H.; Tal, S.; Eichen, Y.; Carell, T. J. Am. Chem. Soc. 2006, 128, 1398.

(11) Scriven, E. F. V.; Turnbull, K. Chem. Rev. 1988, 88, 297.

(12) Hui, H. K.-W.; Shechter, H. Tetrahedron. Lett. 1982, 23, 5115.

(13) (a) Herrmann, W. A.; Schwarz, J.; Gardiner, M. G. Organometallics 1999, 18, 4082. (b) Heckenroth, M.; Kluser, A.; Neels, A.; Albrecht, M. Dalton Trans. 2008, in press (DOI:10.1039/b812405a).

(14) (a) Wang, H. M. J.; Lin, I. J. B. Organometallics 1998, 17, 972. (b) Garrison, J. C.; Youngs, W. J. Chem. Rev. 2005, 105, 3978.

(15) (a) Alcarazo, M.; Roseblade, S. J.; Cowley, A. R.; Fernandez, R.; Brown, J. M.; Lassaletta, J. M. J. Am. Chem. Soc. 2005, 127, 3290. (b) Lavallo, V.; Mafhouz, J.; Canac, Y.; Donnadieu, B.; Schoeller, W. W.; Bertrand, G. J. Am. Chem. Soc. 2004, 126, 8670. (c) Iglesias, M.; Beetstra, D. J.; Stasch, A.; Horton, P. N.; Hursthouse, M. B.; Coles, S. J.; Cavell, K. J.; Dervisi, A.; Fallis, I. A. Organometallics 2007, 26, 4800.

(16) (a) Chianese, A. R.; Li, X.; Janzen, M. C.; Faller, J. W.; Crabtree, R. H. Organometallics 2003, 22, 1663. (b) Kelly, R. A.; Clavier, H.; Giudice, S.; Scott, N. M.; Stevens, E. D.; Bordner, J.; Samardjiev, I.; Hoff, C. D.; Cavallo, L.; Nolan, S. P. Organometallics 2008, 27, 202. 